\title{
Association Between Airflow Limitation and Carotid Intima-Media Thickness in the Japanese Population
}

This article was published in the following Dove Press journal: International Journal of Chronic Obstructive Pulmonary Disease

\author{
Kazuhiko Watanabe' \\ Ayumi Onoue ${ }^{2}$ \\ Hisamitsu Omori ${ }^{2}$ \\ Kenichi Kubota ${ }^{3}$ \\ Minoru Yoshida ${ }^{3}$ \\ Takahiko Katoh' \\ 'Department of Public Health, Faculty of \\ Life Sciences, Kumamoto University, \\ Kumamoto, Japan; ${ }^{2}$ Department of \\ Biomedical Laboratory Sciences, Faculty \\ of Life Sciences, Kumamoto University, \\ Kumamoto, Japan; ${ }^{3}$ apanese Red Cross \\ Kumamoto Health Care Center, \\ Kumamoto, Japan
}

Purpose: This study aimed to reveal the association between airflow limitation (AL) and carotid intima-media thickness (IMT) according to smoking status in Japan.

Subjects and Methods: This cross-sectional study was performed in 2809 subjects, who underwent a comprehensive health examination with pulmonary function tests and carotid ultrasonographic measurement. AL was defined as forced expiratory volume in $1 \mathrm{~s} /$ forced vital capacity of $<0.7$. The subjects were divided into the following four groups: never smokers without AL, never smokers with $\mathrm{AL}$, former/current smokers without AL, and former/current smokers with AL. Mean IMT, the maximum measurable IMT value in the left and right common carotid arteries (IMT-C max), and mean IMT-C max were measured by carotid ultrasonography. The carotid wall thickness as defined as follows: IMT $\geq 1.1 \mathrm{~mm}$ $\left(\mathrm{IMT}_{1.1}\right)$, IMT-C $\max \geq 1.2 \mathrm{~mm}\left(\mathrm{IMTc}_{1.2}\right)$, and IMT-C $\max >1.5 \mathrm{~mm}\left(\mathrm{IMTc}_{1.5}\right)$, based on each measured region. The association between $\mathrm{AL}$ and the carotid wall thickness according to smoking status was assessed by logistic regression analysis.

Results: The mean carotid IMT and mean IMT-C max were significantly higher in never smokers with AL and former/current smokers with or without AL than in never smokers without AL. In logistic regression models adjusted for sex, age, body mass index, hypertension, dyslipidemia, hyperglycemia, physical activity, and alcohol consumption, the risk of carotid wall thickness (IMT ${ }_{1.1}$ [odds ratio $\{\mathrm{OR}\}: 1.55 ; 95 \%$ confidence interval $\{\mathrm{CI}\}: 1.07-2.24$ ]; $\mathrm{IMTc}_{1.2}$ [OR: 1.52; 95\% CI: 1.03-2.24]; IMTc I.. $_{1.0}$ [OR: 1.99; 95\% CI: 1.15-3.46]) were significantly higher in former/current smokers with AL than in never smokers without AL.

Conclusion: The present results suggest that greater IMT and risk of carotid wall thickness were associated with AL and smoking experience.

Keywords: chronic obstructive pulmonary disease, cardiovascular disease, comorbidity, atherosclerosis, airflow limitation, carotid intima-media thickness

\section{Introduction}

Chronic obstructive pulmonary disease (COPD) represents an important public health challenge characterized by persistent respiratory symptoms and airflow limitation (AL), which are both preventable and treatable. ${ }^{1}$ COPD is the third leading cause of death globally, as reported by the World Health Organization in 2016. ${ }^{2}$ The incidence of COPD is likely to increase in the coming years due to an increase in smoking habits and an aging population in several countries. ${ }^{3}$

COPD is regarded as a systemic disease because it can affect other organs beyond the lungs and induce comorbidities. ${ }^{1,4}$ In particular, cardiovascular disease
Correspondence: Hisamitsu Omori Department of Biomedical Laboratory Sciences, Faculty of Life Sciences, Kumamoto University, 4-24-I Kuhonji, Chuo-ku Kumamoto, 862-0976, Japan Tel/Fax+8I-96-373-5462

Email omorih@gpo.kumamoto-u.ac.jp
International Journal of Chronic Obstructive Pulmonary Disease 2021:16 7|5-726 
(CVD) is a common and important comorbidity in COPD ${ }^{1,4-7}$ associated with mortality in patients with COPD. ${ }^{6,8}$ Lung function impairment is associated with the prevalence of $\mathrm{CVD},{ }^{9}$ and reduced forced expiratory volume in 1 second $\left(\mathrm{FEV}_{1}\right)$ has been reported as an independent risk factor for cardiovascular mortality in the general population. ${ }^{10,11}$

Smoking is the leading environmental risk factor for COPD, which is the most well studied. ${ }^{1}$ Smoking is a widely acceptable cause of not only COPD but also CVD. Nevertheless, a multicenter international study has reported that never smokers may also develop AL. ${ }^{12}$ Furthermore, a prospective cohort study has indicated that the relationship between airflow limitation and atherosclerosis was similar in both never smokers and ever smokers. ${ }^{13}$ Therefore, subclinical atherosclerosis should be diagnosed as early as possible in patients with COPD and population with $\mathrm{AL}$ regardless of being smokers or nonsmokers.

Several studies reported that subjects with ischemic heart disease, ${ }^{14} \mathrm{CVD},{ }^{15}$ and coronary artery disease ${ }^{16}$ had a high prevalence of AL compatible with COPD, most of which were undiagnosed and untreated. Similarly, a Japanese multicenter study in outpatients with CVD also demonstrated that the prevalence of $\mathrm{AL}$ $\left(\mathrm{FEV}_{1} / \mathrm{FEV}_{6}\right.$ ratio $\left.<0.73\right)$ was higher and undiagnosed. ${ }^{17}$ Thus, it might be beneficial to find AL in patients with CVD and the population with CVD risk factors.

Several studies have reported that AL was associated with subclinical atherosclerosis that is intima-media thickness (IMT) of carotid artery. ${ }^{18-24}$ Carotid artery ultrasonography, is a non-invasive method, ${ }^{25}$ which has widely been indicated in subjects with risk factors for atherosclerosis and those in whom the possibility of progression to atherosclerosis cannot be ruled out. ${ }^{26}$ An increase in IMT is correlated with atherosclerotic diseases such as cerebral and myocardial infarction and lifestyle-related diseases, which are risks for atherosclerotic diseases. ${ }^{26}$ Recent study demonstrated that IMT measurement value is used as a risk of CVD occurrence in Japanese population. ${ }^{27} \mathrm{~A}$ previous case-control study in Japanese males indicated that carotid IMT was significantly higher in former/current smokers with AL than in control smokers and nonsmokers without pulmonary function abnormalities. ${ }^{18}$ Nevertheless, the relationship between $\mathrm{AL}$ and atherosclerosis in smokers and never smokers is unknown. The currently available data regarding AL and carotid artery IMT in Japanese subjects stratified by smoking status, especially in never smokers, are limited. The aim of this study was to examine the relationship between AL and carotid artery IMT as CVD risk according to smoking status in the Japanese population.

\section{Subjects and Methods Subject Selection}

A total of 46,594 people visited the Japanese Red Cross Kumamoto Health Care Center for medical health checkups between April 2016 and September 2017. Of these, 5875 subjects aged 40 years or above underwent spirometry and measurement of carotid ultrasonography (Figure 1). All subjects underwent a health screening examination that included interview questionnaires, a physical examination, and blood sampling, as previously described. ${ }^{28-34}$ Data on medical history, the use of medications, physical activity, alcohol consumption, and smoking status were obtained in the questionnaires by a trained public health nurse. ${ }^{34}$ Subjects were classified based on their smoking status as never smokers, former smokers, or current smokers. The never smokers consisted of those who had never smoked a cigarette in their lifetime. The former smokers were defined as those who reported smoking cessation prior to the examination, and did not currently smoke. Current smokers were those who currently smoke at the time of the interview. The number of cigarette pack-years was calculated by dividing the average number of cigarettes smoked per day by 20 and multiplying it by the number of years of smoking. All subjects were evaluated by a physician.

Subjects with forced expiratory volume in $1 \mathrm{~s} /$ forced vital capacity $\left(\mathrm{FEV}_{1} / \mathrm{FVC}\right) \geq 70 \%$ and $\mathrm{FEV}_{1}<80 \%$ predicted value $(n=416)$ were excluded from the present study. Subjects with self-reported asthma $(n=266)$, lung cancer $(n=44)$, tuberculosis or pleuritis $(n=53)$, bronchiectasis $(n=16)$, pneumothorax $(n=20)$, pneumonia $(n=$ $125)$, and other respiratory diseases $(n=192)$, those without data for blood sugar $(\mathrm{n}=1845)$ were excluded from our analysis. We also excluded 89 subjects with a history of clinical cardiovascular diseases (78 angina and 11 myocardial infarction). None of the subjects were diagnosed with COPD or had earlier received treatment for the same in the present study.

Data from a total of 2809 subjects (mean age 61.2, standard deviation [SD] 10.3) were included in the final analyses (Figure 1, Table 1). We classified subjects 


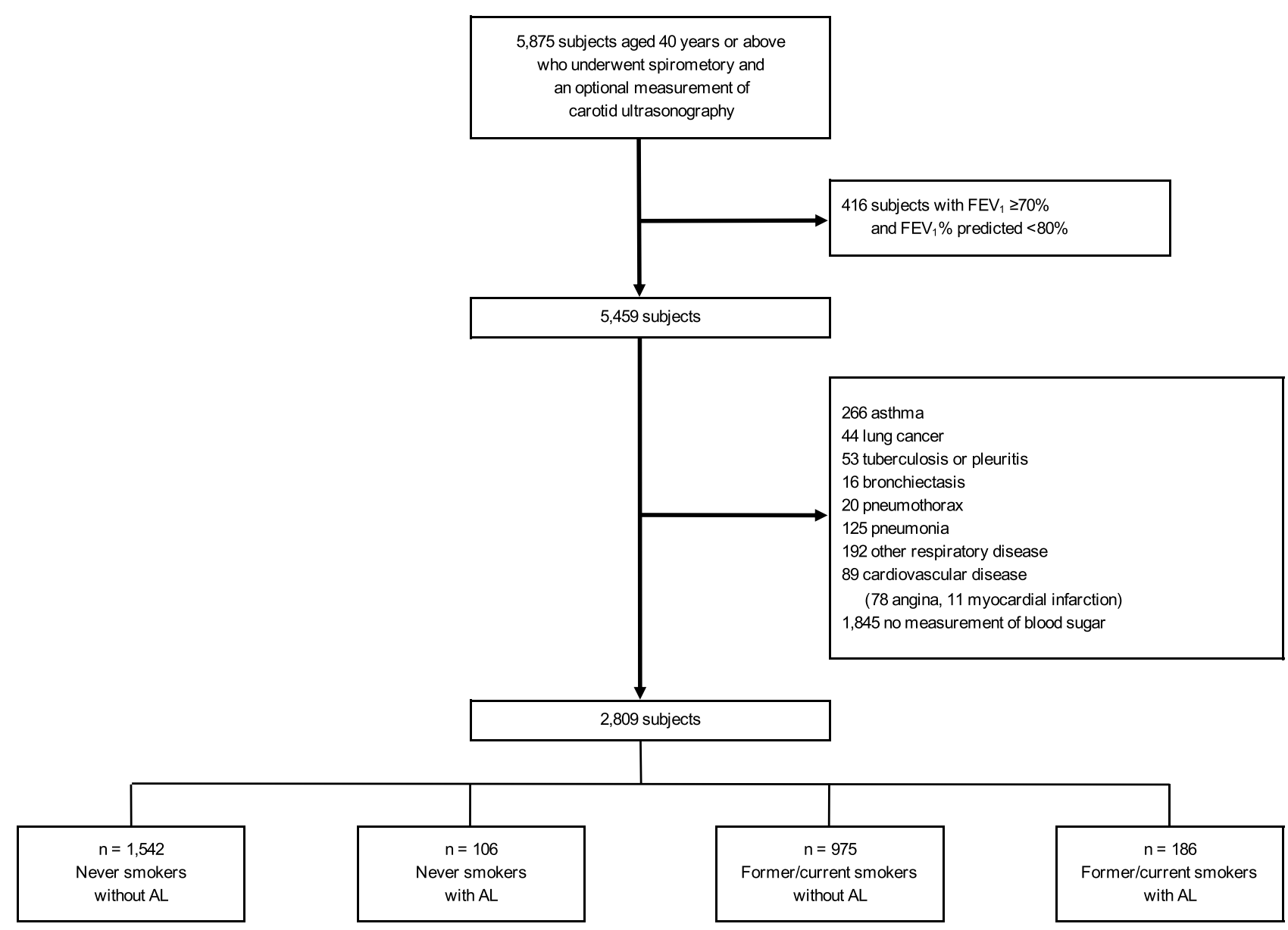

Figure I Flow chart for selecting subjects according to smoking status and $A L$. Abbreviations: $\mathrm{AL}$, airflow limitation; $\mathrm{FEV}_{1}$, forced expiratory volume in I s.

without smoking experience into two groups as follows: never smokers without $\mathrm{AL}$ and never smokers with $\mathrm{AL}$. Similarly, we classified former and current smokers into two groups: former and current smokers without $\mathrm{AL}$ and former and current smokers with AL.

All the subjects in the present study gave their informed consent. This study was conducted in accordance with the Declaration of Helsinki and the Ethical Guidelines for Epidemiological Research (partially revised on December 1, 2008, by the Ministry of Education, Culture, Sports, Science and Technology and the Ministry of Health, Labour and Welfare). The research protocol was approved by the Human Ethics Committee of Kumamoto University (Number 84) and the Japanese Red Cross Kumamoto Health Care Center.

\section{Pulmonary Function Tests}

Pulmonary function was measured using an electronic spirometer (DISCOM-21 FX; CHEST MI, Tokyo, Japan) according to the American Thoracic Society/European Respiratory Society guidelines, ${ }^{35}$ as previously described. ${ }^{28-34}$ Bronchodilator reversibility testing was not performed in the present study. According to the Global Initiative for Chronic Obstructive Pulmonary Disease guidelines, ${ }^{1}$ AL was defined as prebronchodilator $\mathrm{FEV}_{1} / \mathrm{FVC}$ ratio of $<70 \%$. Predicted values were calculated using the equations published by the Japanese Respiratory Society: ${ }^{36}$ males, $0.036 \times$ height $(\mathrm{cm})-0.028 \times$ age -1.178 ; females, $0.022 \times$ height $(\mathrm{cm})$ $-0.022 \times$ age -0.005 . Subjects without AL were defined as having pre-bronchodilator $\mathrm{FEV}_{1} / \mathrm{FVC} \geq 70 \%$ and $\mathrm{FEV}_{1} \geq$ $80 \%$ of predicted values.

\section{Carotid Intima-Media Thickness Measures}

Carotid IMT values were measured by ultrasonography (Aplio Mx; Toshiba, Tokyo, Japan) in the common carotid artery on the left and right sides. ${ }^{25}$ Well-trained medical 
Table I The Characteristics of the Subjects According to Smoking Status and Presence of AL

\begin{tabular}{|c|c|c|c|c|c|}
\hline & $\begin{array}{l}\text { Never Smokers } \\
\text { AL (-) } n=I 542\end{array}$ & $\begin{array}{c}\text { Never Smokers } \\
\text { AL (+) n=106 }\end{array}$ & $\begin{array}{c}\text { Former/Current } \\
\text { Smokers AL }(-) n=975\end{array}$ & $\begin{array}{c}\text { Former/Current } \\
\text { Smokers AL (+) } n=186\end{array}$ & p value \\
\hline Age, yr & $61.0(10.1)$ & $70.0(10.3)^{* *}$ & $59.6(9.8) * *+\dagger$ & $67.4(8.8)^{* * \S \S}$ & $<0.001$ \\
\hline Male, n (\%) & $438(28.4)$ & $37(34.9)$ & $813(83.4)$ & $172(92.5)$ & $<0.001$ \\
\hline Height, cm & $158.6(8.3)$ & $157.6(8.3)$ & $166.2(7.3)^{* * t \dagger}$ & $166.5(7.3)^{* *+\dagger}$ & $<0.001$ \\
\hline Weight, kg & $57.9(11.5)$ & $55.9(10.2)$ & $65.8(11.0)^{* * t \dagger}$ & $64.5(10.0)^{* * \dagger \dagger}$ & $<0.001$ \\
\hline BMI, $\mathrm{kg} / \mathrm{m}^{2}$ & $22.9(3.5)$ & $22.4(3.0)$ & $23.7(3.1)^{* * \dagger \dagger}$ & $23.2(2.8)$ & $<0.001$ \\
\hline $\begin{array}{l}\text { BMI classification, } \mathrm{n}(\%) \\
\text { Underweight: } \mathrm{BMI}<18.5 \\
\text { Normal: } \mathrm{I} 8.5 \leq \mathrm{BMI}<25.0 \\
\text { Over weight: } 25 \leq \mathrm{BMI} \\
\text { Abdominal } \\
\text { circumference, cm }\end{array}$ & $\begin{array}{c}101(6.6) \\
1066(69.1) \\
375(24.3) \\
83.9(9.4)\end{array}$ & $\begin{array}{c}7(6.6) \\
75(70.8) \\
24(22.6) \\
83.6(8.9)\end{array}$ & $\begin{array}{c}31(3.2) \\
639(65.5) \\
305(31.3) \\
86.6(8.7)^{* * \dagger}\end{array}$ & $\begin{array}{c}10(5.4) \\
134(72.0) \\
42(22.6) \\
86.3(8.6)^{*}\end{array}$ & $\begin{array}{l}<0.001 \\
<0.001\end{array}$ \\
\hline $\begin{array}{l}\text { Pulmonary function } \\
\text { FVC, mL Total } \\
\text { Male } \\
\text { Female } \\
\text { FEV }_{1}, \mathrm{~mL} \text { Total } \\
\text { Male } \\
\text { Female }\end{array}$ & $\begin{array}{l}3074.8(751.1) \\
3952.0(638.6) \\
2726.9(447.2) \\
2416.7(603.4) \\
3101.4(522.8) \\
2145.1(374.7)\end{array}$ & $\begin{array}{c}2935.8(835.6) \\
3768.7(700.5) \\
2489.1(488.3)^{* *} \\
1927.8(558.9)^{* *} \\
2457.3(498.4)^{* *} \\
1643.9(341.3)^{* *}\end{array}$ & $\begin{array}{c}3779.8(691.8)^{* *+\dagger} \\
3955.7(597.7) \\
2897.0(391.9)^{* *+\dagger} \\
2935.6(554.8)^{* * \dagger \dagger} \\
3070.7(485.8)^{\dagger \dagger} \\
2257.5(342.3)^{* *+\dagger}\end{array}$ & $\begin{array}{c}3593.8(727.5)^{* * \dagger \dagger \S} \\
3666.2(694.6)^{* * 8 \S} \\
2704.3(515.2) \\
2304.6(511.5)^{\dagger \dagger \S \S} \\
2347.9(495.6)^{* * \delta \S} \\
1772.1(402.0)^{* * \S \S}\end{array}$ & $\begin{array}{l}<0.001 \\
<0.001 \\
<0.001 \\
<0.001 \\
<0.001 \\
<0.001\end{array}$ \\
\hline $\mathrm{FEV}_{\mathrm{I}} / \mathrm{FVC}, \%$ & $78.7(5.0)$ & $65.7(3.0)^{* *}$ & $77.8(4.6)^{* * t \dagger}$ & $64.1(5.3)^{* * \$ \S}$ & $<0.001$ \\
\hline $\mathrm{FEV}_{1} \%$ predicted, $\%$ & $102.8(12.9)$ & $89.2(12.8)^{* *}$ & $97.6(10.9)^{* *+\dagger}$ & $80.3(13.8)^{* * t+\S \S}$ & $<0.001$ \\
\hline $\mathrm{SBP}, \mathrm{mm} \mathrm{Hg}$ & $125.7(16.7)$ & $130.0(\mid 5.8)$ & I $26.7(\mid 5.2)$ & $|30.|(15.0)^{* *}$ & 0.007 \\
\hline $\mathrm{DBP}, \mathrm{mm} \mathrm{Hg}$ & $73.7(11.0)$ & $73.8(11.3)$ & $76.6(10.7)^{* *}$ & $76.4(11.3)^{*}$ & $<0.001$ \\
\hline Pack-years & $0(0)$ & $0(0)$ & $21.1(17.8)^{* *+\dagger}$ & $33.6(24.6)^{* *+\dagger \S \S}$ & $<0.001$ \\
\hline $\begin{array}{l}\text { Physical activity, n (\%) } \\
\text { Inactivity } \\
\text { Regular activity }\end{array}$ & $\begin{array}{l}670(43.5) \\
872(56.5)\end{array}$ & $\begin{array}{l}47(44.3) \\
59(55.7)\end{array}$ & $\begin{array}{l}381(39.1) \\
594(60.9)\end{array}$ & $\begin{array}{l}77(4 \mathrm{I} .4) \\
109(58.6)\end{array}$ & 0.173 \\
\hline $\begin{array}{l}\text { Alcohol consumption, n (\%) } \\
\text { Non } \\
\text { I-6 days per week } \\
\text { Daily }\end{array}$ & $\begin{array}{c}933(60.5) \\
498(32.3) \\
111(7.2)\end{array}$ & $\begin{array}{c}66(62.2) \\
34(32.1) \\
6(5.7)\end{array}$ & $\begin{array}{l}221(22.7) \\
466(47.8) \\
288(29.5)\end{array}$ & $\begin{array}{l}49(26.3) \\
81(43.6) \\
56(30.1)\end{array}$ & $<0.001$ \\
\hline 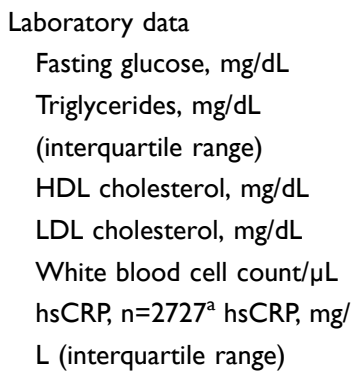 & $\begin{array}{c}99.7(13.9) \\
86.00 \\
(63.75-121.00) \\
67.5(16.8) \\
128.2(28.3) \\
4974.8(1245.8) \\
n=1495^{\mathrm{a}} 0.06 \\
(0.03-0.11)^{\mathrm{a}}\end{array}$ & $\begin{array}{c}101.8(21.1) \\
87.00 \\
(62.75-117.25) \\
70.4(19.3) \\
123.8(28.6) \\
4950.0(1222.8) \\
n=104^{\mathrm{a}} 0.06 \\
(0.04-0.11)^{\mathrm{a}}\end{array}$ & $\begin{array}{c}105.1(16.5)^{* *} \\
105.00 \\
(74.00-154.00)^{* *+\dagger} \\
62.0(16.9)^{* * t \dagger} \\
124.7(28.2)^{*} \\
5456.7(1505.3)^{* * \dagger \dagger} \\
n=942^{\mathrm{a}} 0.07 \\
(0.04-0.12)^{\mathrm{a}}\end{array}$ & $\begin{array}{c}105 . I(14.8)^{* *} \\
107.50 \\
(79.75-147.25)^{* * \dagger} \\
60.6(16.7)^{* * \dagger \dagger} \\
115.0(29.6)^{* * \S \S} \\
5625.3(1635.8)^{* * \dagger \dagger} \\
n=1860.07 \\
(0.04-0.15)^{* * \S \S}\end{array}$ & $\begin{array}{l}<0.001 \\
<0.001 \\
<0.001 \\
<0.001 \\
<0.001 \\
0.005\end{array}$ \\
\hline
\end{tabular}


Table I (Continued).

\begin{tabular}{|c|c|c|c|c|c|}
\hline & $\begin{array}{l}\text { Never Smokers } \\
\text { AL (-) } n=1542\end{array}$ & $\begin{array}{l}\text { Never Smokers } \\
\text { AL (+) } n=106\end{array}$ & $\begin{array}{c}\text { Former/Current } \\
\text { Smokers AL (-) n=975 }\end{array}$ & $\begin{array}{c}\text { Former/Current } \\
\text { Smokers AL (+) n=186 }\end{array}$ & p value \\
\hline \multicolumn{6}{|l|}{ Clinical information, n (\%) } \\
\hline Hypertension & $806(52.3)$ & $69(65.1)$ & $559(57.3)$ & $130(69.9)$ & $<0.001$ \\
\hline Hyperglycemia & $238(15.4)$ & $17(16.0)$ & $257(26.4)$ & $5 I(27.4)$ & $<0.001$ \\
\hline Dyslipidemia & $917(59.5)$ & $74(69.8)$ & $577(59.2)$ & $105(56.5)$ & 0.143 \\
\hline
\end{tabular}

Notes: Data are expressed as means (standard deviation), median (interquartile range), or as number ( $\mathrm{n}$ ) (percentage). $\mathrm{AL}$ was defined as $\mathrm{FEV} / \mathrm{FVC}<0.7$. Pack-years $=$ (average number of cigarettes smoked per day $\times$ number of year of smoking)/20. ahsCRP data were only recorded for 2727 of the 2809 total subjects, 1495 of I542 never smokers without AL, 104 of the 106 never smokers with AL, and 942 of 975 former/current smokers without AL. Hypertension was defined as SBP of $\geq 130$ mm Hg, DBP of $\geq 85 \mathrm{~mm} \mathrm{Hg}$, and/or current use of antihypertensive medication. Hyperglycemia was defined as a fasting blood glucose level of $\geq 1 \mathrm{I} 0 \mathrm{mg} / \mathrm{dL}$ and/or the current use of blood glucose lowering medication. Dyslipidemia was defined as triglycerides $\geq 150 \mathrm{mg} / \mathrm{dL}$, LDL-C $\geq 140 \mathrm{mg} / \mathrm{dL}$, HDL-C $<40 \mathrm{mg} / \mathrm{dL}$, and/or current use of medication. *P $<0.05$, ${ }^{* *} \mathrm{p}<0.0$ l compared with never smokers without $\mathrm{AL} .{ }^{\dagger} \mathrm{p}<0.05,{ }^{\dagger \dagger} \mathrm{p}<0.01$ compared with never smokers with $\mathrm{AL}$. ${ }^{\S} \mathrm{p}<0.05$, ${ }^{\S \S} \mathrm{p}<0.0 \mathrm{l}$ compared with former and current smokers without AL.

Abbreviations: $A L$, airflow limitation; $A L(-)$, without $A L ; A L(+)$, with $A L ; B M I$, body mass index; FVC, forced vital capacity; FEV, forced expiratory volume in I s; SBP, systolic blood pressure; DBP, diastolic blood pressure; HDL, high-density lipoprotein; LDL, low-density lipoprotein; hsCRP, high-sensitivity C-reactive protein.

technologists performed all the examinations. Mean IMT was defined as the average of IMT values in both the right and left sides of the common carotid arteries. IMT-C max was defined as the maximum measurable IMT value in the left and right common carotid arteries. Mean IMT-C max was computed as the average of both the right and left IMT-C max values. In the present study, we defined the carotid wall thickness as follows: IMT $\geq 1.1 \mathrm{~mm}\left(\mathrm{IMT}_{1.1}\right)$, IMT-C $\max \geq 1.2 \mathrm{~mm}\left(\operatorname{IMTc}_{1.2}\right)$, and IMT-C $\max >$ $1.5 \mathrm{~mm}\left(\mathrm{IMTc}_{1.5}\right)$, based on each measured region. The criteria of $\mathrm{IMT}_{1.1}$ and $\mathrm{IMT}_{1.5}$ are used to evaluate carotid artery plaque according to the guidelines. ${ }^{25}$ The criterion of $\mathrm{IMTc}_{1.2}$ was suggested to be the risk of CVD in the Japanese general population. ${ }^{27}$ Therefore, we defined these three criteria as the carotid wall thickness of subclinical atherosclerosis in this study.

\section{Physical Examination and Blood Measurements}

Body mass index (BMI) was calculated by dividing the body weight $(\mathrm{kg})$ by the square of the height $\left(\mathrm{m}^{2}\right)$. BMI was classified as follows: underweight $(<18.5)$, normal weight $(18.5 \leq \mathrm{BMI}<25.0)$, and overweight $(\geq 25.0){ }^{37}$ Subjects abdominal circumference was measured at the end of a normal expiration in a standing position. Physical activity was divided into two categories: "regular physical activity" was defined as engaging in sports or other forms of exercise at least once weekly regularly, and "physical inactivity" was defined as engaging in irregular physical activity or no form of physical activity. ${ }^{34}$ Subjects were classified based on alcohol consumption as "nondrinkers," "consuming alcohol for 1-6 days per week," and "daily drinkers." 34 After overnight fasting, fasting glucose, triglycerides, highdensity lipoprotein cholesterol (HDL-C), low-density lipoprotein cholesterol (LDL-C), white blood cell (WBC) count, and high-sensitivity C-reactive protein (hsCRP) were measured in serum samples. Before blood samples were obtained, subjects were placed at rest.

\section{Clinical Information}

Trained nurses measured systolic blood pressure (SBP) and diastolic blood pressure (DBP) using an automatic digital sphygmomanometer (HEM-904; OMRON, Kyoto, Japan), which was placed on the upper arm at the height of the heart with the subject in a seated position. ${ }^{34}$ Subjects were rest for at least 5 minutes before the initial BP reading was obtained. The SBP and DBP were taken to be the average of two measurements. Hypertension was defined as $\mathrm{SBP}$ of $\geq 130 \mathrm{~mm} \mathrm{Hg}, \mathrm{DBP}$ of $\geq 85 \mathrm{~mm} \mathrm{Hg}$, and/or current use of antihypertensive medication.

Hyperglycemia was defined as a fasting blood glucose level of $\geq 110 \mathrm{mg} / \mathrm{dL}$ and/or the current use of blood glucose lowering medication. Dyslipidemia was defined as triglycerides $\geq 150 \mathrm{mg} / \mathrm{dL}$, LDL-C $\geq 140 \mathrm{mg} / \mathrm{dL}$, HDL-C $<40 \mathrm{mg} / \mathrm{dL}$, and/or current use of medication. ${ }^{28}$

\section{Statistical Analyses}

Data are expressed as number of cases with percentages, mean (SD), or median with interquartile range. Bar graphs presented mean values, and error bars indicated SD. Normality of data was assessed using the Shapiro-Wilk test. Analysis of variance (ANOVA), Kruskal-Wallis test, and $\chi^{2}$ test were used to assess the differences in characteristics among never smokers without AL, never smokers 
with AL, former and current smokers without AL, and former and current smokers with AL. Post-hoc analysis comparing differences in characteristics between groups was done using Scheffe's test. The effects of AL and smoking, as well as the interaction of these factors in IMT and IMT-C max were verified by two-way ANOVA and Scheffe's post-hoc test.

Multivariate logistic regression models were used to examine the association between AL and carotid wall thickness according to smoking status. Statistical significance was defined as $\mathrm{p}<0.05$. All statistical analyses were performed with the IBM SPSS Statistics 22.0 software (IBM Corporation, Armonk, NY, USA).

\section{Results}

\section{Study Population Characteristics}

The present study subjects had a mean age of 61.2 years with $52.0 \%$ were males, $41.3 \%$ were former or current smokers, and $10.4 \%$ had AL.

Table 1 shows the characteristics of the subjects according to smoking status and presence of AL. A total of 2809 subjects were included in the final analysis. The mean age of never smokers with AL and former/current smokers with AL was significantly higher than that in never smokers without AL. Former/current smoker groups included many males compared to never smokers. The subjects in former/current smoker groups were taller with higher weight than those in the never smoker group. Former and current smokers without AL had significantly higher BMI than those in the never smoker group. In particular, the number of subjects who were overweight $(\mathrm{BMI} \geq 25)$ were higher $(31.3 \%, \mathrm{n}=305)$ than the other groups. Abdominal circumference was significantly larger in the former and current smoker groups than in never smokers without AL. Former and current smoker groups had significantly higher FVC, mean DBP, fasting glucose level, triglyceride level, WBC count, and prevalence of hyperglycemia than those in the never smoker group. Similarly, the number of alcohol drinkers in former and current smoker groups was larger than those in the never smoker group. HDL-C and LDL-C levels were significantly lower in the former and current smoker groups than in never smokers without AL. Median hsCRP level was significantly higher in former and current smokers with AL than in the other groups. Mean SBP was higher in the former and current smokers with AL than in never smokers without $\mathrm{AL}$, and the highest prevalence of hypertension was $69.9 \%$ in former and current smokers with AL. There was no significant difference in physical activity and prevalence of dyslipidemia among the groups.

\section{Association Between $\mathrm{AL}$ and Mean Carotid IMT Values According to Smoking Status}

Table 2 shows the effects of AL and smoking on IMT and IMT-C max assessed by two-way ANOVA. There was a significant additive interaction between $\mathrm{AL}$ and smoking in IMT $(\mathrm{F}=7.33, \mathrm{p}=0.007)$ and IMT-C max values $(\mathrm{F}=$ $6.37, \mathrm{p}=0.012)$. Therefore, we compared mean IMT and IMT-C max values in the four groups stratified by AL and smoking status (Figures 2 and 3).

Mean IMT was significantly higher in never smokers with AL $(0.98 \mathrm{~mm})(\mathrm{p}=0.026)$, former/current smokers without AL $(0.93 \mathrm{~mm})(\mathrm{p}=0.024)$, and former/current smokers with AL $(1.12 \mathrm{~mm})(\mathrm{p}<0.001)$ than those in never smokers without AL $(0.90 \mathrm{~mm})$ (Figure 2). Additionally, the mean IMT in former/current smokers with AL $(1.12 \mathrm{~mm})$ was significantly higher than that in both never smokers with $\mathrm{AL}(0.98 \mathrm{~mm})(\mathrm{p}=0.002)$ and former/current smokers without AL $(0.93 \mathrm{~mm})(\mathrm{p}<0.001)$ (Figure 2). Similarly, mean IMT-C max in never smokers with $\mathrm{AL}(0.98 \mathrm{~mm})(\mathrm{p}=0.014)$, former/current smokers without AL $(0.92 \mathrm{~mm})(\mathrm{p}=0.037)$, and former/current smokers with AL $(1.10 \mathrm{~mm})(\mathrm{p}<0.001)$ were significantly

Table 2 The Effects of AL and Smoking on IMT and IMT-C Max

\begin{tabular}{|c|c|c|c|c|c|c|c|c|c|c|}
\hline & \multicolumn{2}{|l|}{$\mathbf{A L}$} & \multirow[b]{2}{*}{$\mathbf{F}$} & \multicolumn{2}{|l|}{ Smoking } & \multirow[b]{2}{*}{$\mathbf{F}$} & \multicolumn{2}{|c|}{ AL Plus Smoking } & \multirow[b]{2}{*}{$\mathbf{F}$} & \multirow[b]{2}{*}{$\mathrm{p}$ value } \\
\hline & $\begin{array}{l}\text { Yes } \\
(n=292)\end{array}$ & $\begin{array}{l}\text { No } \\
(n=25 \mid 7)\end{array}$ & & $\begin{array}{l}\text { Yes } \\
(n=1 \mid 6 I)\end{array}$ & $\begin{array}{l}\text { No } \\
(n=1648)\end{array}$ & & $\begin{array}{l}\text { Yes } \\
(n=\mid 86)\end{array}$ & $\begin{array}{l}\text { No } \\
(n=\mid 542)\end{array}$ & & \\
\hline IMT & $\mathrm{I} .07(0.37)$ & $0.91(0.27)$ & $55.67^{* *}$ & $0.96(0.33)$ & $0.90(0.25)$ & $21.78 * *$ & $1.12(0.42)$ & $0.90(0.25)$ & $7.33^{* *}$ & 0.007 \\
\hline IMT-C max & $\mathrm{I} .06(0.37)$ & $0.90(0.27)$ & $57.99 * *$ & $0.95(0.33)$ & $0.89(0.25)$ & $19.20 * *$ & $1.10(0.43)$ & $0.88(0.25)$ & $6.37^{*}$ & 0.012 \\
\hline
\end{tabular}

Notes: Data are expressed as means (standard deviation). AL was defined as $\mathrm{FEV}_{\mathrm{l}} / \mathrm{FVC}<0.7$. Smoking was defined as former or current smoking. ${ }^{*} \mathrm{p}<0.05$, ** $<0.0 \mathrm{I}$. Abbreviations: AL, airflow limitation; IMT, intima-media thickness; IMT-C max, the maximum measurable IMT value in the left and right common carotid arteries. 


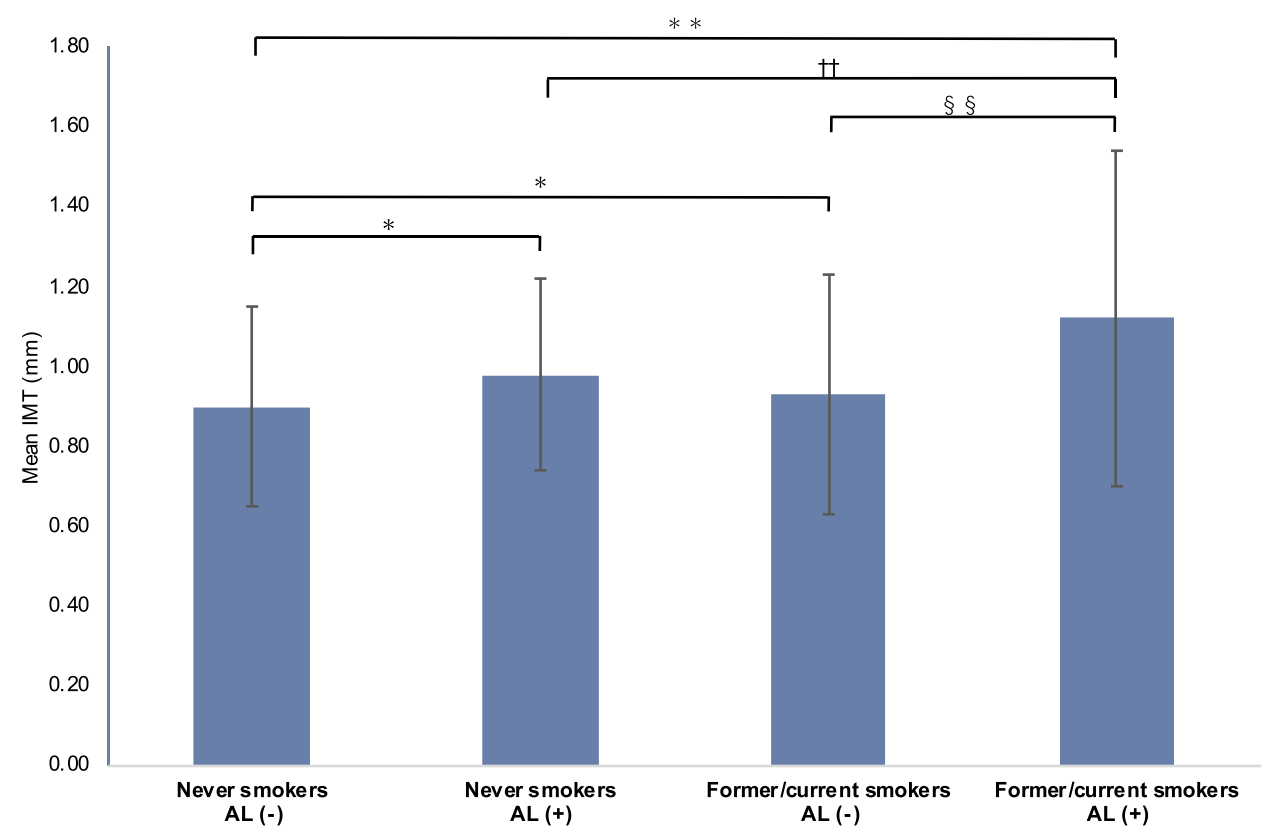

Figure 2 Association between $\mathrm{AL}$ and mean IMT values according to smoking status.

Notes: Data are expressed as means (standard deviation). AL was defined as FEV $/$ FVC $<0.7$. Mean IMT was defined as the average of IMT values in both the right and left sides of the common carotid arteries. ${ }^{*} \mathrm{p}<0.05$, ${ }^{* *} \mathrm{p}<0.01$ compared with never smokers without $\mathrm{AL}$. ${ }^{\dagger \dagger} \mathrm{p}<0.0 \mathrm{l}$ compared with never smokers with $\mathrm{AL}$. ${ }^{\S} \mathrm{p}<0.0 \mathrm{l}$ compared with former/current smokers without AL. Error bars indicate standard deviation.

Abbreviations: $A L$, airflow limitation; $A L(-)$, without $A L ; A L(+)$, with $A L ; I M T$, intima-media thickness.

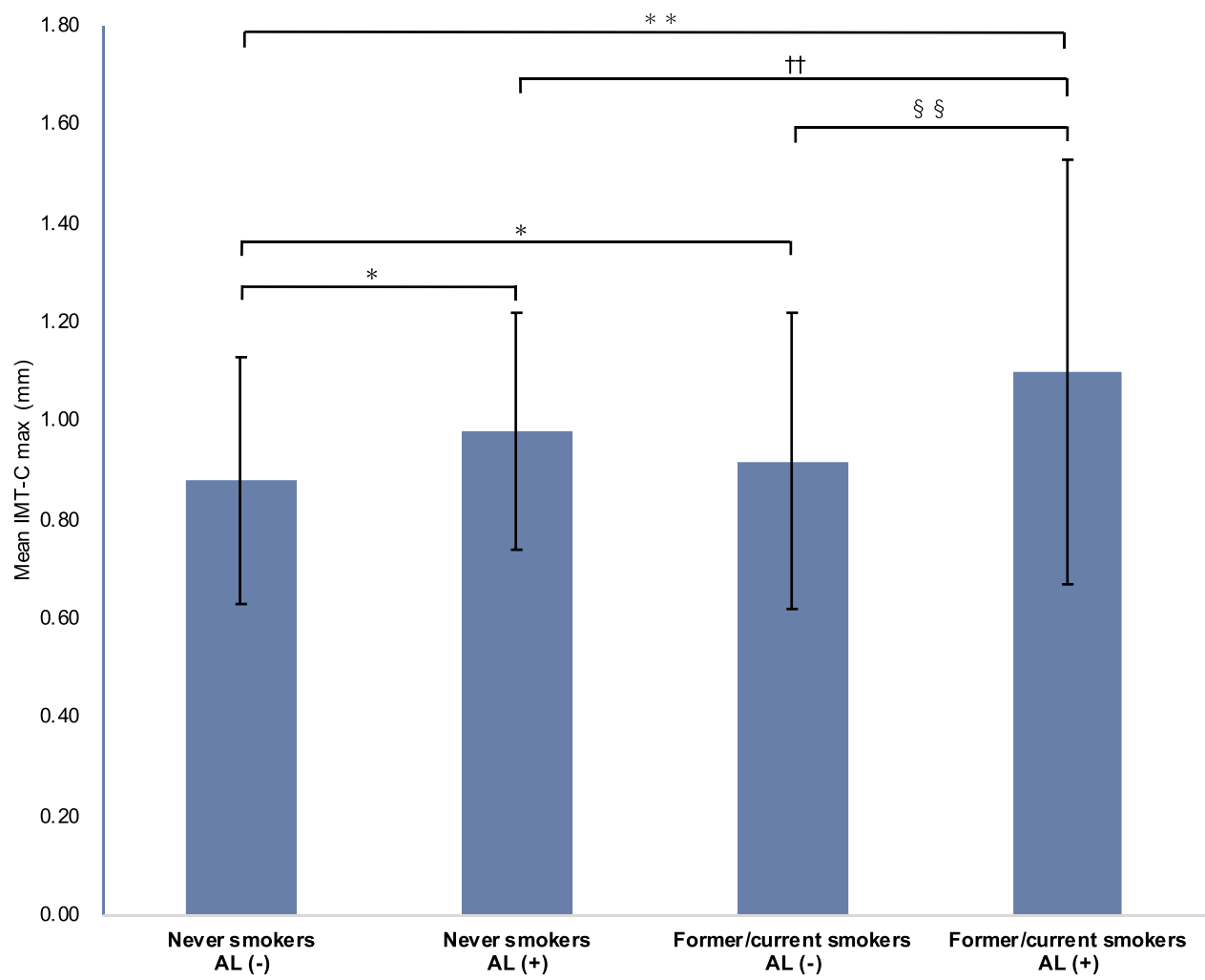

Figure 3 Association between $A L$ and mean IMT-C max values according to smoking status.

Notes: Data are expressed as means (standard deviation). AL was defined as FEV $/$ FVC $<0.7$. IMT-C max was defined as the maximum measurable IMT value in the left and right common carotid arteries. Mean IMT-C max was defined as the average of both the right and left IMT-C max values. *P $<0.05$, **p $<0.01$ compared with never smokers without $A L .{ }^{\dagger+} P<0.01$ compared with never smokers with $A L$. ${ }^{\S \S} \mathrm{P}<0.01$ compared with former/current smokers without AL. Error bars indicate standard deviation. Abbreviations: $A L$, airflow limitation; $A L(-)$, without $A L ; A L(+)$, with $A L ; I M T$, intima-media thickness. 
Table 3 Association Between AL and Carotid Wall Thickness According to Smoking Status

\begin{tabular}{|c|c|c|c|c|c|c|c|}
\hline & \multicolumn{2}{|c|}{ Never Smokers } & \multirow[b]{2}{*}{ p value } & \multicolumn{3}{|c|}{ Former/Current Smokers } & \multirow[b]{2}{*}{ p value } \\
\hline & AL (-) & AL (+) & & AL (-) & $\mathrm{p}$ value & AL (+) & \\
\hline & $n=1542$ & $n=106$ & & $n=975$ & & $n=186$ & \\
\hline \multicolumn{8}{|l|}{$\mathrm{IMT}_{1 . \mathrm{I}}$} \\
\hline Crude & I.00 (Reference) & $2.11(1.42-3.13)^{* *}$ & $<0.001$ & $1.25(1.05-1.48)^{*}$ & 0.012 & $3.29(2.4 I-4.50)^{* *}$ & $<0.001$ \\
\hline Model I & I.00 (Reference) & $1.03(0.67-1.6 I)$ & 0.883 & $0.99(0.79-1.23)$ & 0.898 & $1.50(1.05-2.15)^{*}$ & 0.028 \\
\hline Model 2 & I.00 (Reference) & $1.01(0.65-1.58)$ & 0.965 & $0.97(0.78-\mid .2 I)$ & 0.793 & $1.53(1.06-2.20)^{*}$ & 0.024 \\
\hline Model 3 & I.00 (Reference) & $1.00(0.64-1.56)$ & 0.998 & I.0I (0.80-I.27) & 0.939 & $1.55(1.07-2.24)^{*}$ & 0.020 \\
\hline \multicolumn{8}{|l|}{$\mathrm{IMT}_{\mathrm{CI} .2}$} \\
\hline Crude & I.00 (Reference) & $2.10(1.35-3.27)^{* *}$ & 0.001 & $1.59(1.30-1.94)^{* *}$ & $<0.001$ & $3.44(2.48-4.75)^{* *}$ & $<0.001$ \\
\hline Model I & I.00 (Reference) & $1.03(0.64-1.68)$ & 0.896 & $1.21(0.94-1.57)$ & 0.135 & $1.54(1.06-2.25)^{*}$ & 0.024 \\
\hline Model 2 & I.00 (Reference) & $1.01(0.62-1.64)$ & 0.978 & $1.21(0.94-1.57)$ & 0.146 & $1.54(1.05-2.26)^{*}$ & 0.028 \\
\hline Model 3 & I.00 (Reference) & $1.00(0.61-1.63)$ & 0.999 & $1.20(0.92-1.57)$ & 0.169 & $1.52(1.03-2.24)^{*}$ & 0.034 \\
\hline \multicolumn{8}{|l|}{${ }_{I M T} T_{C I .5}$} \\
\hline Crude & I.00 (Reference) & $0.91(0.32-2.54)$ & 0.850 & $1.79(1.26-2.53)^{* *}$ & 0.001 & $4.44(2.79-7.06)^{* *}$ & $<0.001$ \\
\hline Model I & I.00 (Reference) & $0.47(0.17-1.35)$ & 0.161 & $1.35(0.89-2.04)$ & 0.163 & $2.05(1.21-3.48)^{* *}$ & 0.008 \\
\hline Model 2 & I.00 (Reference) & $0.46(0.16-1.32)$ & 0.148 & $1.36(0.89-2.09)$ & 0.154 & $2.05(1.19-3.52)^{*}$ & 0.010 \\
\hline Model 3 & I.00 (Reference) & $0.48(0.17-1.38)$ & 0.175 & $1.30(0.84-2.02)$ & 0.232 & $1.99(1.15-3.46)^{*}$ & 0.014 \\
\hline
\end{tabular}

Notes: Model I: adjusted for sex, age, and BMI. Model 2: adjusted for covariates in Model I plus hypertension, hyperglycemia, and dyslipidemia. Model 3: adjusted for covariates in Model 2 plus physical activity and alcohol consumption. AL was defined as $\mathrm{FEV}_{1} / \mathrm{FVC}<0.7$. IMT $\mathrm{II}_{1.1}$ was defined as measurable IMT value in the left, right, or both common carotid arteries $\geq 1.1 \mathrm{~mm}$. IMT $\mathrm{CI}_{\mathrm{I} .2}$ was defined as the maximum measurable IMT value in the left, right, or both common carotid arteries $\geq 1.2 \mathrm{~mm}$. IMT $\mathrm{CI}_{\mathrm{I} .5}$ was defined as the maximum measurable IMT value in the left, right, or both common carotid arteries $>1.5 \mathrm{~mm}$. ${ }^{*} \mathrm{p}<0.05$, **p $<0.01$.

Abbreviations: $A L$, airflow limitation; $A L(-)$, without $A L ; A L(+)$, with $A L ; I M T$, intima-media thickness.

higher than those in never smokers without $\operatorname{AL}(0.88 \mathrm{~mm})$ (Figure 3). In addition, the mean IMT-C max in former/ current smokers with AL $(1.10 \mathrm{~mm})$ was also significantly higher than that in both never smokers with AL $(0.98 \mathrm{~mm})$ $(\mathrm{p}=0.004)$ and former/current smokers without AL $(0.92 \mathrm{~mm})(\mathrm{p}<0.001)$ (Figure 3).

\section{Association Between $\mathrm{AL}$ and Carotid Wall Thickness According to Smoking Status}

Table 3 shows the association between AL and carotid wall thickness as $\mathrm{IMT}_{1.1}, \mathrm{IMTc}_{1.2}$, and IMTc $\mathrm{IM}_{1.5}$. The OR of $\mathrm{IMT}_{1.1}, \mathrm{IMTc}_{1.2}$, and $\mathrm{IMTc}_{1.5}$ were significantly higher in former/current smokers with AL (OR: 1.55; 95\% CI: 1.07-2.24, OR: 1.52; 95\% CI: 1.03-2.24, OR: 1.99; 95\% CI: 1.15-3.46, respectively) than in never smokers without AL after adjusting for sex, age, BMI, hypertension, dyslipidemia, hyperglycemia, physical activity, and alcohol consumption (all $\mathrm{p}<0.05$ ). However, the OR of $\mathrm{IMT}_{1.1}$, $\mathrm{IMTc}_{1.2}$, and $\mathrm{IMTc}_{1.5}$ in never smokers with AL (OR: 1.00; 95\% CI: 0.64-1.56, OR: 1.00; 95\% CI: 0.61-1.63, OR: $0.48 ; 95 \% \mathrm{CI}: 0.17-1.38$, respectively) and former/ current smokers without AL (OR: 1.01; 95\% CI:
0.80-1.27, OR: 1.20; 95\% CI: 0.92-1.57, OR: 1.30; 95\% CI: 0.84-2.02, respectively) were not significantly different from those in never smokers without AL.

\section{Discussion}

We demonstrated that mean IMT and mean IMT-C max were higher in never smokers with $\mathrm{AL}$ and former/current smokers with or without AL than in never smokers without AL. In the logistic regression models, adjusted for sex, age, BMI, hypertension, dyslipidemia, hyperglycemia, physical activity, and alcohol consumption, a combination AL and smoking experience was associated with carotid wall thickness in the present study.

Several studies have demonstrated an association between $\mathrm{FEV}_{1}$ and carotid atherosclerosis in the general population. A previous study of middle-aged males showed that mean IMT was significantly higher in former/current smokers with AL than in former/current smokers and never smokers without AL. ${ }^{18}$ The MESA Lung Study and the ARIC study demonstrated that decreased $\mathrm{FEV}_{1}$ was associated with increased carotid IMT in the former and current smokers. ${ }^{19,20}$ Our findings were similar to the above results. In the present study, we examined clinical covariates including physical activity and alcohol 
consumption as CVD risk factors. Moreover, we included never smokers with AL, and excluded subjects with a history or clinical evidence of clinical CVD (myocardial infraction or angina). Thus, we examined more subjects and comprehensive range of clinical CVD risk factors.

Although more females were included in the never smoker group, we found that mean IMT and mean IMT$\mathrm{C}$ max values were higher in never smokers with AL than in those without AL in the present study. However, the three ORs of carotid wall thickness were not significantly different among the never smoker's group in logistic regression models after adjusting for clinical covariates. In the never smoker group, only the mean age was higher in those with AL compared to those without AL, except for pulmonary function status, and there was no significant difference in both hsCRP and WBC at baseline. A recent Japanese study investigated the association between cigarette smoking and subclinical atherosclerosis in a general population and showed that the mean IMT value was not significantly different in never smokers and former/current smokers. ${ }^{38}$ However, their pulmonary function was not examined. Therefore, not only smoking exposure but also presence of AL might be associated with greater carotid IMT among the general population.

Epidemiological studies showed that elevated CRP levels were related to an increased risk of cardiac injury in those with moderate airflow obstruction, ${ }^{39}$ and is associated with increased CVD in those with detectable atherosclerosis based on carotid ultrasound. ${ }^{40}$ Although AL severity was not examined, elevated hsCRP levels were observed in smokers with AL in the present study, which might indicate the risk of cardiac injury or CVD.

Many studies have investigated the association between pulmonary abnormalities and atherosclerosis in patients with COPD or the general population; nevertheless, the causal mechanisms linking AL, atherosclerosis, and CVD are not fully understood. Low-grade, chronic systemic inflammation is considered one of the key mechanisms underlying systemic manifestations beyond the lungs, including CVD. ${ }^{41,42}$ A previous report showed that, compared with healthy controls, individuals with chronic AL had significantly increased levels of CRP, fibrinogen, leucocytes, and tumor necrosis factor- $\alpha$, indicating that even among non-current smokers, there was evidence of low-grade systemic inflammation in those with AL. ${ }^{43}$ Of these inflammation markers, fibrinogen and hsCRP are recognized as markers of systemic inflammation in COPD. Previous studies have shown that these markers are useful predictors of cardiovascular events in the general population. ${ }^{44}$ Moreover, a study of individuals with COPD demonstrated that increased levels of a combination of CRP, fibrinogen, and leukocyte count were associated with increased risk of ischemic heart disease, myocardial infarction, heart failure, type II diabetes, lung cancer, and pneumonia, and that risk estimates were largely independent of smoking. ${ }^{45}$ We did not evaluate other inflammatory markers including fibrinogen; thus, further research is needed to reveal AL involvement and inflammation in atherosclerosis. On the other hand, a recent report indicated that endothelial cell dysfunction and AL were mutually independent predictors of atherosclerosis. ${ }^{46}$ AL could be an important predictor of atherosclerosis markers in the general population.

This study has several limitations. First, we included all subjects meeting inclusion criteria, aged 40 years or above; thus, it might increase the risk of confounding by age in subjects with AL. In addition, because we assessed males and females together, therefore, many females were included in the never smoker group. Therefore, sex differences might be a confounding factor for IMT values, which we were unable to determine in our findings. Nevertheless, we precluded these involvements by adjusting in logistic regression analysis.

Second, post-bronchodilator spirometry measurements were not performed because of the absence of high suspicion of clinical disease; thus, some subjects with $\mathrm{AL}$ may have a post-bronchodilator $\mathrm{FEV}_{1} / \mathrm{FVC} \geq 70 \%$ in the present study. However, we excluded respiratory diseases other than COPD, including asthma, at the subject selection. Therefore, it is likely that the subjects with AL had COPD.

Third, because we examined cross-sectional associations in the present study, we cannot address the temporal relationship between AL and IMT. Therefore, prospective studies are needed to confirm these findings. The detailed mechanisms underlying AL and greater IMT are unclear, except for active smoking, for example, secondhand smoke might be the cause of AL in the never smoker group. However, we did not have available data for these in the present study.

Despite these limitations, presence of AL and smoking experience may be effective in screening for subclinical atherosclerosis in subjects undiagnosed with COPD. In our results, screening for subclinical atherosclerosis using IMT as an indicator might be useful to prevent future CVD in smokers with AL.

In the present study, we observed subjects with AL, who might have been diagnosed with COPD in $10 \%$ of all subjects. Moreover, although a small number of ALs was 
observed in never smokers, their mean IMT and mean IMT-C max were higher in those with AL than in those without AL. However, the ORs for carotid wall thickness were not significantly different between the never smoker groups. Therefore, greater IMT in never smokers with AL might not require immediate clinical intervention. Similarly, the ORs for carotid wall thickness were not significantly different in former/current smokers without AL than in never smokers without AL after adjusting for CVD risk factors. In contrast, the ORs for carotid wall thickness were significantly higher in former/current smokers with AL than in never smokers without AL in logistic regression models adjusted for CVD risk factors. Additionally, mean IMT and IMT-C max values were greater in former/current smokers with $\mathrm{AL}$ than in never smokers with or without $\mathrm{AL}$ and former/current smokers without AL. Hence, a combination of AL and smoking seemed to be a risk factor for carotid wall thickness.

Nevertheless, mean IMT and mean IMT-C max were greater in former/current smokers with AL than in former/ current smokers without AL, and in never smokers with AL than in never smokers without AL. Considering that there was a significant interaction between AL and smoking status in IMT values, more studies are needed to further confirm the effect of AL on IMT in never smokers.

Even so, from the perspective of preventing CVD or arteriosclerosis and atherosclerotic lesions, it is important to identify the presence of these risks regardless of smoking status before clinical symptoms appear. According to a report that $\mathrm{CVD}$ comorbidities appeared to be independent of AL severity in COPD, ${ }^{47,48}$ early AL diagnosis might be useful to prevent subclinical AL progression and to identify cardiovascular risk factors at an earlier stage in subjects with undiagnosed COPD. Because COPD risk factors are not only active smoking but also secondhand smoke and environmental factors such as exposure to indoor and outdoor air pollution, occupational dust, and fumes, ${ }^{1}$ the early diagnosis of AL in the general population regardless of smoking status may lead to determining the CVD risk factors.

To our knowledge, this is the first study to examine the association between AL and carotid IMT among never smokers in the Japanese population. Efforts aimed at the earlier detection of AL regardless of smoking experience in the general population and identification of greater carotid IMT in smokers may lead to the reduction of the burden of COPD on the society.

\section{Conclusion}

In summary, we showed that mean IMT in former/current smokers with $\mathrm{AL}$ was higher than that in never smokers with or without $\mathrm{AL}$ and former/current smokers without AL. Additionally, the risk of carotid wall thickness was higher in former and current smokers with AL than in never smokers without AL. Therefore, it might be beneficial to find risk factors for CVD earlier in smokers with AL for preventing future CVD occurrence. In addition, $\mathrm{AL}$ may be an early indicator of subclinical arteriosclerosis in smokers and never smokers in preventing atherosclerotic diseases. Our findings suggest that $\mathrm{AL}$ and smoking experience are markers to recognize subclinical atherosclerosis in the Japanese general population.

\section{Abbreviations}

AL, airflow limitation; ANOVA, analysis of variance; BMI, body mass index; CVD, cardiovascular disease; COPD, chronic obstructive pulmonary disease; DBP, diastolic blood pressure; $\mathrm{FEV}_{1}$, forced expiratory volume in 1 second; $\mathrm{FEV}_{6}$, forced expiratory volume in 6 second; FVC, forced vital capacity; HDL-C, high-density lipoprotein cholesterol; hsCRP, high-sensitivity C-reactive protein; IMT, intima-media thickness; LDL-C, low-density lipoprotein cholesterol; OR, odds ratio; SBP, systolic blood pressure; SD, standard deviation; WBC, white blood cell.

\section{Acknowledgments}

The authors would like to thank the staff of the Japanese Red Cross Kumamoto Health Care Center for their excellent technical support. We would to like thank Editage for English language editing.

\section{Author Contributions}

All authors made a significant contribution to the work reported, whether that is in the conception, study design, execution, acquisition of data, analysis and interpretation, or in all these areas; took part in drafting, revising or critically reviewing the article; gave final approval of the version to be published; have agreed on the journal to which the article has been submitted; and agree to be accountable for all aspects of the work.

\section{Disclosure}

The authors have no conflicts of interest in this article. 


\section{References}

1. Global Initiative for Chronic Obstructive Lung Disease. Global strategy for the diagnosis, management, and prevention of chronic obstructive pulmonary disease; 2020. Available from: https://gold copd.org. Accessed August 28, 2020.

2. World Health Organization. Available from: https://www.who.int/ gho/mortality_burden_disease/causes_death/top_10/en/. Accessed August 28, 2020.

3. World health organization. Chronic obstructive pulmonary disease (COPD). Available from: https://www.who.int/news-room/factsheets/detail/chronic-obstructive-pulmonary-disease-(copd).

Accessed August 30, 2020.

4. Japanese Respiratory Society. The JRS Guidelines for the Management of Chronic Obstructive Pulmonary Disease. 5th ed Tokyo: Medical Review Co., Ltd; 2018.

5. Chen W, Thomas J, Sadatsafavi M, FitzGerald JM. Risk of cardiovascular comorbidity in patients with chronic obstructive pulmonary disease: a systematic review and meta-analysis. Lancet Respir Med. 2015;3(8):631-639. doi:10.1016/S2213-2600(15)00241-6

6. Barnes PJ, Celli BR. Systemic manifestations and comorbidities of COPD. Eur Respir J. 2009;33(5):1165-1185. doi:10.1183/ 09031936.00128008

7. Müllerova H, Agusti A, Erqou S, Mapel DW. Cardiovascular comorbidity in COPD: systematic literature review. Chest. 2013;144 (4):1163-1178. doi:10.1378/chest.12-2847

8. Miller J, Edwards LD, Agustí A, et al. Comorbidity, systemic inflammation and outcomes in the ECLIPSE cohort. Respir Med. 2013;107 (9):1376-1384. doi:10.1016/j.rmed.2013.05.001

9. Johnston AK, Mannino DM, Hagan GW, Davis KJ, Kiri VA. Relationship between lung function impairment and incidence or recurrence of cardiovascular events in a middle-aged cohort. Thorax. 2008;63(7):599-605. doi:10.1136/thx.2007.088112

10. Shibata Y, Inoue S, Igarashi A, et al. A lower level of forced expiratory volume in 1 second is a risk factor for all-cause and cardiovascular mortality in a Japanese population: the Takahata study. PLoS One. 2013;8(12):e83725. doi:10.1371/journal.pone.0083725

11. Sin DD, Wu L, Paul Man SF. The relationship between reduced lung function and cardiovascular mortality: a population-based study and a systematic review of the literature. Chest. 2005;127(6):1952-1959. doi:10.1378/chest.127.6.1952

12. Lamprecht B, McBurnie MA, Vollmer WM, et al. COPD in never smokers: results from the population-based burden of obstructive lung disease study. Chest. 2011;139(4):752-763. doi:10.1378/chest.10-1253

13. Gudmundsson G, Margretardottir OB, Sigurdsson MI, et al. Airflow obstruction, atherosclerosis and cardiovascular risk factors in the AGES Reykjavik study. Atherosclerosis. 2016;252:122-127. doi:10.1016/j.atherosclerosis.2016.07.919

14. Franssen FME, Soriano JB, Roche N, et al. Lung function abnormalities in smokers with ischemic heart disease. Am J Respir Crit Care Med. 2016;194(5):568-576. doi:10.1164/rccm.201512-2480OC

15. Soriano JB, Rigo F, Guerrero D, et al. High prevalence of undiagnosed airflow limitation in patients with cardiovascular disease. Chest. 2010;137(2):333-340. doi:10.1378/chest.09-1264

16. Almagro P, Lapuente A, Pareja J, et al. Underdiagnosis and prognosis of chronic obstructive pulmonary disease after percutaneous coronary intervention: a prospective study. Int J Chron Obstruct Pulmon Dis. 2015;10:1353-1361. doi:10.2147/COPD.S84482

17. Onishi K, Yoshimoto D, Hagan GW, Jones PW. Prevalence of airflow limitation in outpatients with cardiovascular diseases in Japan. Int J Chron Obstruct Pulmon Dis. 2014;9:563-568. doi:10.2147/ COPD.S59962

18. Iwamoto H, Yokoyama A, Kitahara Y, et al. Airflow limitation in smokers is associated with subclinical atherosclerosis. Am J Respir Crit Care Med. 2009;179(1):35-40. doi:10.1164/rccm.200804$560 \mathrm{OC}$
19. Barr RG, Ahmed FS, Carr JJ, et al. Subclinical atherosclerosis, airflow obstruction and emphysema: the MESA Lung Study. Eur Respir J. 2012;39(4):846-854. doi:10.1183/09031936.00165410

20. Schroeder EB, Welch VL, Evans GW, Heiss G. Impaired lung function and subclinical atherosclerosis. The ARIC Study. Atherosclerosis. 2005;180(2):367-373. doi:10.1016/j.atherosclerosis.2004.12.012

21. Ebrahim S, Papacosta O, Whincup P, et al. Carotid plaque, intima media thickness, cardiovascular risk factors, and prevalent cardiovascular disease in men and women: the British Regional Heart Study. Stroke. 1999;30(4):841-850. doi:10.1161/01.str.30.4.841

22. Sugiura T, Dohi Y, Takagi Y, et al. Close association between subclinical atherosclerosis and pulmonary function in middle-aged male smokers. J Atheroscler Thromb. 2020:14. doi:10.5551/jat.55996

23. Kudo K, Hata J, Matsumoto K, et al. Association of Airflow Limitation With Carotid Atherosclerosis in a Japanese Community - The Hisayama Study. Circ J. 2017;81 (12):1846-1853. doi:10.1253/circj.CJ-16-1305

24. Lahousse L, van den Bouwhuijsen QJA, Loth DW, et al. Chronic obstructive pulmonary disease and lipid core carotid artery plaques in the elderly: the Rotterdam Study. Am J Respir Crit Care Med. 2013;187(1):58-64. doi:10.1164/rccm.201206-1046OC

25. Terminology and Diagnostic Criteria Committee, Japan society of ultrasonics in medicine, subcommittee for guidelines for ultrasound diagnosis of carotid artery. Standard method for ultrasound evaluation of carotid artery lesions, 2017. Available from https://www.jsum. or.jp/committee/diagnostic/pdf/jsum0515_guideline.pdf. Accessed July 5, 2020.

26. Terminology and Diagnostic Criteria Committee, Japan Society of Ultrasonics in Medicine. Standard method for ultrasound evaluation of carotid artery lesions. J Med Ultrason. 2009;36(4):219-226. doi:10.1007/s10396-009-0238-y

27. Kokubo Y, Watanabe M, Higashiyama A, Nakao YM, Nakamura F, Miyamoto Y. Impact of Intima-Media Thickness Progression in the Common Carotid Arteries on the Risk of Incident Cardiovascular Disease in the Suita Study. J Am Heart Assoc. 2018;7(11):e007720. doi:10.1161/JAHA.117.007720

28. Oda M, Omori H, Onoue A, et al. Association between airflow limitation severity and arterial stiffness as determined by the brachial-ankle pulse wave velocity: a cross-sectional study. Intern Med. 2015;54(20):2569-2575. doi:10.2169/internalmedicine.54.3778

29. Omori H, Nagano M, Funakoshi Y, et al. Twelve-year cumulative incidence of airflow obstruction among Japanese males. Intern Med. 2011;50(15):1537-1544. doi:10.2169/internalmedicine.50.4412

30. Onoue A, Omori H, Katoh T, et al. Relationship of airflow limitation severity with work productivity reduction and sick leave in a Japanese working population. Int J Chron Obstruct Pulmon Dis. 2016;16(11):567-575. doi:10.2147/COPD.S99786

31. Omori H, Tsuji M, Sata K, et al. Correlation of C-reactive protein with disease severity in CT diagnosed emphysema. Respirology. 2009;14(4):551-558. doi:10.1111/j.1440-1843.2009.01519.x

32. Masuda S, Omori H, Onoue A, et al. Comorbidities according to airflow limitation severity: data from comprehensive health examination in Japan. Environ Health Prev Med. 2017;22(1):13. doi:10.1186/ s12199-017-0620-0

33. Omori H, Kaise T, Suzuki T, Hagan G. Prevalence of airflow limitation in subjects undergoing comprehensive health examination in Japan: survey of Chronic Obstructive pulmonary disease Patients Epidemiology in Japan. Int J Chron Obstruct Pulmon Dis. 2016;22 (11):873-880. doi:10.2147/COPD.S99935

34. Watanabe K, Onoue A, Kubota K, et al. Association between airflow limitation severity and reduced bone mineral density in Japanese men. Int J Chron Obstruct Pulmon Dis. 2019;14:2355-2363. doi:10.2147/COPD.S213746

35. Miller MR, Hankinson J, Brusasco V, et al. Standardisation of spirometry. Eur Respir J. 2005;26(2):319-338. doi:10.1183/ 09031936 
36. Japanese Respiratory Society. Reference values for spirometry in Japanese adult [Internet]. Available from: http://www.jrs.or.jp/mod ules/guidelines/index.php?content_id=12. Accessed September 3, 2020.

37. World Health Organ Tech Rep Ser. Obesity: preventing and managing the global epidemic. Report WHO Consultation. 2000;894:1-253.

38. Kiriyama H, Kaneko H, Itoh H, et al. Effect of cigarette smoking on carotid artery atherosclerosis: a community-based cohort study. Heart Vessels. 2020;35(1):22-29. doi:10.1007/s00380-019-01455-5

39. Sin DD, Paul Man SF. Why are patients with chronic obstructive pulmonary disease at increased risk of cardiovascular diseases? The potential role of systemic inflammation in chronic obstructive pulmonary disease. Circulation. 2003;107(11):1514-1519. doi:10.1161/ 01.cir.0000056767.69054.b3

40. Cao JJ, Arnold AM, Manolio TA, et al. Association of carotid artery intima-media thickness, plaques, and C-reactive protein with future cardiovascular disease and all-cause mortality: the Cardiovascular Health Study. Circulation. 2007;116(1):32-38. doi:10.1161/ CIRCULATIONAHA.106.645606

41. Sinden NJ, Stockley RA. Systemic inflammation and comorbidity in COPD: a result of 'overspill' of inflammatory mediators from the lungs? Review of the evidence. Thorax. 2010;65(10):930-936. doi:10.1136/thx.2009.130260

42. Agusti A, Soriano JB. COPD as a systemic disease. COPD. 2008;5 (2):133-138. doi:10.1080/15412550801941349
43. Gan WQ, Man SFP, Senthilselvan A, Sin DD. Association between chronic obstructive pulmonary disease and systemic inflammation: a systematic review and a meta-analysis. Thorax. 2004;59 (7):574-580. doi:10.1136/thx.2003.019588

44. Kaptoge S, Di Angelantonio E, Pennells L, et al. C-reactive protein, fibrinogen, and cardiovascular disease prediction. $N$ Engl J Med. 2012;367(14):1310-1320. doi:10.1056/NEJMoa1107477

45. Thomsen M, Dahl M, Lange P, Vestbo J, Nordestgaard BG. Inflammatory biomarkers and comorbidities in chronic obstructive pulmonary disease. Am J Respir Crit Care Med. 2012;186 (10):982-988. doi:10.1164/rccm.201206-1113OC

46. Chandra D, Gupta A, Strollo PJ, et al. Airflow limitation and endothelial dysfunction. Unrelated and independent predictors of atherosclerosis. Am J Respir Crit Care Med. 2016;194(1):38-47. doi:10.1164/rccm.201510-2093OC

47. Agusti A, Calverley PM, Celli B, et al. Characterisation of COPD heterogeneity in the ECLIPSE cohort. Respir Res. 2010;11(1):122. doi:10.1186/1465-9921-11-122

48. Suzuki M, Makita H, Ito YM, Nagai K, Konno S, Nishimura M. Hokkaido COPD Cohort Study Investigators. Clinical features and determinants of COPD exacerbation in the Hokkaido COPD cohort study. Eur Respir J. 2014;43(5):1289-1297. doi:10.1183/ 09031936.00110213

\section{Publish your work in this journal}

The International Journal of COPD is an international, peer-reviewed journal of therapeutics and pharmacology focusing on concise rapid reporting of clinical studies and reviews in COPD. Special focus is given to the pathophysiological processes underlying the disease, intervention programs, patient focused education, and self management protocols. This journal is indexed on PubMed Central, MedLine and CAS. The manuscript management system is completely online and includes a very quick and fair peer-review system, which is all easy to use. Visit http://www.dovepress.com/testimonials.php to read real quotes from published authors. 